\title{
Pulmonary endarterectomy for distal chronic thromboembolic pulmonary hypertension
}

\author{
Andrea M. D'Armini, MD, ${ }^{\mathrm{a}, \mathrm{b}}$ Marco Morsolini, MD, PhD, ${ }^{\mathrm{a}}$ Gabriella Mattiucci, MD, ${ }^{\mathrm{a}, \mathrm{b}}$ \\ Valentina Grazioli, MD, ${ }^{\mathrm{a}, \mathrm{b}}$ Maurizio Pin, MD,${ }^{\mathrm{b}}$ Adele Valentini, MD, ${ }^{\mathrm{c}}$ Giuseppe Silvaggio, MD, ${ }^{\mathrm{b}}$ \\ Catherine Klersy, MD, MSc, ${ }^{\mathrm{d}}$ and Roberto Dore, $\mathrm{MD}^{\mathrm{c}}$
}

\begin{abstract}
Objectives: Chronic thromboembolic pulmonary hypertension can be cured by pulmonary endarterectomy. Operability assessment remains a major concern, because there are no well-defined criteria to discriminate proximal from distal obstructions, and surgical candidacy depends mostly on the surgeon's experience. The intraoperative classification of chronic thromboembolic pulmonary hypertension describes 4 types of lesions, based on anatomy and location. We describe our recent experience with the more distal (type 3) disease.
\end{abstract}

Methods: More than 500 pulmonary endarterectomies were performed at Foundation I.R.C.C.S. Policlinico San Matteo (Pavia, Italy). Because of recent changes in the patient population, 331 endarterectomies performed from January 2008 to December 2013 were analyzed. Two groups of patients were identified according to the intraoperative classification: proximal (type 1 and type 2 lesions, 221 patients) and distal (type 3 lesions, 110 patients).

Results: The number of endarterectomies for distal chronic thromboembolic pulmonary hypertension increased significantly over time (currently $\sim 37 \%$ ). Deep venous thrombosis was confirmed as a risk factor for proximal disease, whereas patients with distal obstruction had a higher prevalence of indwelling intravascular devices. Overall hospital mortality was $6.9 \%$, with no difference in the 2 groups. Postoperative survival was excellent. In all patients, surgery was followed by a significant and sustained improvement in hemodynamic, echocardiographic, and functional parameters, with no difference between proximal and distal cases.

Conclusions: Although distal chronic thromboembolic pulmonary hypertension represents the most challenging situation, the postoperative outcomes of both proximal and distal cases are excellent. The diagnosis of inoperable chronic thromboembolic pulmonary hypertension should be achieved only in experienced centers, because many patients who have been deemed inoperable might benefit from favorable surgical outcomes. (J Thorac Cardiovasc Surg 2014;148:1005-12)

\section{Supplemental material is available online.}

From the Department of Clinical-Surgical, Diagnostic and Pediatric Sciences, ${ }^{a}$ University of Pavia School of Medicine, Pavia, Italy; and Cardiac Surgery, ${ }^{\mathrm{b}}$ Institute of Radiology, ${ }^{\mathrm{c}}$ and Service of Biometry and Clinical Epidemiology, ${ }^{\mathrm{d}}$ Foundation I.R.C.C.S. Policlinico San Matteo, Pavia, Italy.

Dr Morsolini was supported by an Investigator Fellowship from Collegio Ghislieri, Pavia, Italy.

Disclosures: Dr D'Armini has received consultancy and speaker fees from Bayer HealthCare and Actelion Pharmaceuticals Ltd. Dr Morsolini has received speaker fees from Bayer HealthCare. All other authors have nothing to disclose with regard to commercial support.

Read at the 94th Annual Meeting of The American Association for Thoracic Surgery, Toronto, Ontario, Canada, April 26-30, 2014.

Andrea M. D'Armini and Marco Morsolini contributed equally to this work and should be considered co-first authors.

Received for publication April 8, 2014; revisions received June 17, 2014; accepted for publication June 27, 2014

Address for reprints: Andrea M. D'Armini, MD, Divisione di Cardiochirurgia, Università degli Studi di Pavia, Fondazione I.R.C.C.S. Policlinico San Matteo, Viale Golgi 19, 27100 Pavia, Italy (E-mail: darmini@smatteo.pv.it or andreamaria.darmini@unipv.it).

0022-5223/\$36.00

Copyright $\odot 2014$ by The American Association for Thoracic Surgery

http://dx.doi.org/10.1016/j.jtcvs.2014.06.052
Chronic thromboembolic pulmonary hypertension (CTEPH) can be cured in most patients with pulmonary endarterectomy (PEA). ${ }^{1-9}$ Because there are no welldefined criteria to discriminate surgically accessible from inaccessible obstructive lesions, the operability assessment relies only on the surgeon's decision. ${ }^{10,11}$ Despite growing experience worldwide, and although currently available tools are adequate in identifying the presence of pulmonary arterial obstruction at a distal level, the criteria for operability remain variable and center-dependent. ${ }^{3}$ Because a significant proportion of patients with CTEPH may be deemed inoperable over concerns of distal and surgically inaccessible disease, patients should not be considered inoperable unless they have been evaluated by an experienced surgeon.

Assessment of the severity of pulmonary hypertension in relation to the location of arterial obstructions is essential for surgical candidacy. An excessive increase in pulmonary vascular resistance (PVR) alone, usually greater than 1000 to $1200 \mathrm{dyn} \cdot \mathrm{s} \cdot \mathrm{cm}^{-5}$ in the reported series, ${ }^{3,4,12}$ should not be considered a contraindication to PEA, because patients will benefit from surgery performed by an experienced surgeon. ${ }^{11}$ Because persistent pulmonary hypertension is 


\section{Abbreviations and Acronyms \\ $\mathrm{CI}=$ confidence interval \\ $\mathrm{CTEPH}=$ chronic thromboembolic pulmonary hypertension \\ PEA = pulmonary endarterectomy \\ PVR = pulmonary vascular resistance \\ WHO $=$ World Health Organization}

one of the most important determinants of surgical outcome, ${ }^{4,13}$ the preoperative identification of patients with severe CTEPH and little thromboembolic lesions with concomitant small-vessel disease is crucial. Several techniques are being studied to attempt to partition the upstream from downstream pulmonary resistance, but they remain investigational. ${ }^{14,15}$

The current article shows the outcome of patients with distal CTEPH undergoing PEA at a single experienced center in a recent series, emphasizing the efficacy of the developed operative technique that allows resection of thromboembolic lesions at a subsegmental level with excellent results.

\section{METHODS}

\section{Patient Selection}

From April 11, 1994, to March 31, 2014, 546 consecutive patients diagnosed with CTEPH underwent PEA. A prospective database, approved by the institutional review board, records patients' information. All patients provided informed consent. Except for urgent or emergency operations, all patients with CTEPH admitted to Foundation I.R.C.C.S. Policlinico San Matteo (Pavia, Italy) underwent a complete diagnostic workup according to our published standardized protocol. ${ }^{16,17}$ From 2005 onward, the operability assessment was performed by the same surgeon.

Underlying severe parenchymal lung disease is the only contraindication to PEA at Foundation I.R.C.C.S. Policlinico San Matteo. Some authors also consider the severity of hemodynamic impairment, associated medical conditions, and patient age. ${ }^{3,18}$ During the last 5 years, only 7 patients were excluded from surgery on the basis of only age and preoperative conditions, compared with 322 PEAs performed.

Regardless of preoperative findings, pulmonary arteries are always explored bilaterally during surgery, because imaging tools may fail to detect partially obstructed or recanalized arteries or intraluminal webs, which are almost regularly perfused by contrast agent. With the emerging evidence that some unexpected distal arterial obstructions could be successfully removed intraoperatively, the line between accessible and inaccessible lesions has been pushed more distally over time, contributing to the learning curve of the center. During the year 2013,99 patients with CTEPH were evaluated and 92 patients were deemed operable, for an operability rate of $93 \%$.

At Foundation I.R.C.C.S. Policlinico San Matteo, 331 consecutive PEAs were performed from January 1, 2008, to December 31, 2013. Two groups of patients were identified according to the intraoperative Jamieson's classification $^{10}$ : proximal (type 1 and type 2 lesions, 221 patients) and distal (type 3 lesions, 110 patients). Four patients with intraoperative type 4 CTEPH were excluded from the analysis; 2 patients underwent successful rescue heart-lung transplantation, and they are still alive at 49-month and 8-month follow-ups; 1 patient was successfully weaned from cardiopulmonary bypass and is doing well on combination therapy with 2 specific pulmonary vasodilator agents; and 1 patient was not listed for transplantation because of absolute contraindication and died early postoperatively.

\section{Surgical Technique}

A permanent inferior vena cava filter is placed the day before surgery, unless contraindicated. In 34 patients $(10.3 \%)$, the device was not placed because of the following contraindications: metal allergy (17), inferior vena cava abnormality (6) or complete thrombosis (4), presence of intravascular catheters as a trigger for microembolism (6), and thalassemia (1).

The surgical approach is carried out according to the published surgical technique, ${ }^{19}$ except for some technical details described previously. ${ }^{9}$ From 2007 onward, a combination of multiple short (7-10 minutes) intermittent sessions of circulatory arrest with moderate hypothermia $\left(24^{\circ} \mathrm{C}\right)$, interrupted by adequate ( $\geq 5$-minute) periods of reperfusion driven by continuous near-infrared spectroscopy monitoring, represents the procedure of choice. ${ }^{20}$ In our experience, despite long cumulative circulatory arrest times, this alternative cardiopulmonary bypass management was safe and associated with an increased rate of uncomplicated recovery, with a trend toward reduced neurologic events. Given the extra dissection time that allowed more distal disease to be cleared, the operability rate could be extended. By reducing the burden of deep hypothermia, this technique could be an effective alternative to the original technique in case of distal disease in particularly frail patients, including the elderly.

Norepinephrine and dobutamine (or epinephrine) are routinely administered to assist weaning from cardiopulmonary bypass by improving the systemic perfusion pressure, including coronary blood flow. When indicated, inhaled nitric oxide is administered to improve right ventricular function, notably if PVR is not yet back to normal.

After PEA, the cardiac output is generally high because of the remarkable unloading of the hypertrophic right ventricle and may lead to lung reperfusion edema. Thus, inotropes and inhaled nitric oxide are rapidly discontinued, vasopressor agents are continued for a few days, and a vigorous diuresis is achieved to obtain negative fluid balance. A protective ventilation (high positive end-expiratory pressure and low tidal volume) is preferred to prevent both lung reperfusion edema and ventilation-induced lung injury. Extubation is performed as soon as possible, switching to helmet continuous positive airways pressure ventilation usually for a few days.

\section{Statistical Analysis}

Data are presented as mean and standard deviation and $95 \%$ confidence interval (CI) or median and 25th to 75 th percentiles, if continuous, and counts and percent, if categoric; comparison between groups was performed with the Student $t$ test or Mann-Whitney $U$ test and the Fisher exact test, respectively. Log transformation was used when indicated. The association of intraoperative classification and postoperative acute events was assessed with Fisher exact test; the risk difference $(95 \% \mathrm{CI})$ and the risk ratio $(95 \% \mathrm{CI})$ were computed.

Survival was plotted according to the Kaplan-Meier method and compared between groups with the log-rank test. Mortality per 100 person-years was computed. Hazard ratios $(95 \% \mathrm{CI})$ were derived from the Cox model. Generalized linear models with identity or logit link with Huber-White robust standard errors (to account for within-patient correlation of measures) were fitted to compare the clinical, functional, and hemodynamic outcomes over time between groups.

The comparison of the time profile for each group relied on a Wald test of interaction of group and treatment. Because of the low number of events, no multivariable analysis for hospital and follow-up mortality could be performed. Stata 12.1 (StataCorp LP, College Station, Tex) was used for computation. All tests were 2-sided. Bonferroni correction was used for post hoc comparisons.

\section{RESULTS}

Because of the learning curve, the number of PEA operations in patients with type 3 CTEPH increased significantly over a 6 -year period $(P=.035$, Fisher exact test), as shown in Figure E1. 
TABLE 1. Preoperative concomitant diseases, underlying medical conditions, and presenting characteristics

\begin{tabular}{|c|c|c|c|}
\hline & Proximal & Distal & \\
\hline & $\mathbf{N}=\mathbf{2 2 1}$ & $\mathbf{N}=\mathbf{1 1 0}$ & $P$ value \\
\hline \multicolumn{4}{|c|}{ Preoperative concomitant diseases and underlying medical conditions } \\
\hline Age (y) & $61 \pm 15(59-63)$ & $60 \pm 14(58-63)$ & .578 \\
\hline Female (n) & $119(53.8)$ & $74(67.3)$ & .024 \\
\hline $\operatorname{LOD}(\mathrm{y})$ & $2(1-5)$ & $2(1-5)$ & .851 \\
\hline $\operatorname{BMI}\left(\mathrm{kg} / \mathrm{m}^{2}\right)$ & $26 \pm 5(26-27)$ & $25 \pm 5(24-26)$ & .095 \\
\hline $\mathrm{BMI}<22 \mathrm{~kg} / \mathrm{m}^{2}(\mathrm{n})$ & $41(18.6)$ & $33(30.0)$ & .025 \\
\hline $\mathrm{BMI} \geq 30 \mathrm{~kg} / \mathrm{m}^{2}(\mathrm{n})$ & $43(19.5)$ & $22(20.0)$ & 1.000 \\
\hline Smokers (n) & $19(8.6)$ & $8(7.3)$ & .788 \\
\hline Previous DVT (n) & $134(60.6)$ & $42(38.2)$ & $<.001$ \\
\hline Intravascular devices (n) & $8(3.6)$ & $11(10.0)$ & .024 \\
\hline Splenectomy (n) & $4(1.8)$ & $4(3.6)$ & .448 \\
\hline Blood groups non-0 (n) & $168(76.0)$ & $74(67.3)$ & .114 \\
\hline Oxygen supply (n) & $112(50.7)$ & $49(44.6)$ & .297 \\
\hline Urgent/emergency (n) & $28(12.7)$ & $7(6.4)$ & .217 \\
\hline Medication for PAH (n) & $38(17.2)$ & $33(30.0)$ & .010 \\
\hline Systemic arterial hypertension (n) & $88(39.8)$ & $39(35.5)$ & .473 \\
\hline Dyslipidemia (n) & $58(26.2)$ & $25(22.7)$ & .505 \\
\hline Diabetes (n) & $12(5.4)$ & $4(3.6)$ & .593 \\
\hline Coronary artery disease (n) & $15(6.8)$ & $12(10.9)$ & .386 \\
\hline Chronic obliterative arterial disease (n) & $4(1.8)$ & $2(1.8)$ & 1.000 \\
\hline Atrial fibrillation (n) & $21(9.5)$ & $3(2.7)$ & .058 \\
\hline Chronic renal failure (n) & $16(7.2)$ & $6(5.5)$ & 644 \\
\hline History of cancer (n) & $21(9.5)$ & $10(9.1)$ & 1.000 \\
\hline Neurologic disorders (n) & $17(7.7)$ & $8(7.3)$ & 627 \\
\hline \multicolumn{4}{|l|}{ Presenting characteristics } \\
\hline mPAP (mm Hg) & $44 \pm 10(43-46)$ & $46 \pm 10(44-48)$ & .153 \\
\hline PVR (dyne $\cdot \mathrm{s} \cdot \mathrm{cm}^{-5}$ ) & $876 \pm 392(823-929)$ & $926 \pm 337(862-989)$ & .236 \\
\hline $\mathrm{CO}(\mathrm{L} / \mathrm{min})$ & $3.9 \pm 1.3(3.7-4.1)$ & $3.7 \pm 1.2(3.5-4.0)$ & .315 \\
\hline $\mathrm{CI}\left(\mathrm{L} / \mathrm{min} / \mathrm{m}^{2}\right)$ & $2.1 \pm 0.6(2.0-2.2)$ & $2.2 \pm 0.6(2.0-2.3)$ & .526 \\
\hline $\mathrm{BNP}(\mathrm{pg} / \mathrm{mL})$ & $189(61-459)$ & $188(68-396)$ & .571 \\
\hline NT-proBNP (pg/mL) & $1382(392-3192)$ & $1290(444-2279)$ & .225 \\
\hline TAPSE $(\mathrm{mm})$ & $17 \pm 4(16-18)$ & $17 \pm 4(16-18)$ & .901 \\
\hline Moderate-to-severe TR (n) & $146(66.4)$ & $75(68.2)$ & .804 \\
\hline $\mathrm{PAO}_{2}(\mathrm{~mm} \mathrm{Hg})$ & $65 \pm 12(64-67)$ & $66 \pm 11(64-68)$ & .773 \\
\hline WHO class (II/III/IV) $(\%)$ & $12 / 53 / 35$ & $15 / 54 / 31$ & .597 \\
\hline Modified Bruce exercise test (m) & $51(0-143)$ & $52(0-102)$ & .738 \\
\hline 6-min walking distance $(\mathrm{m})$ & $277 \pm 118(261-294)$ & $289 \pm 112(267-310)$ & .424 \\
\hline
\end{tabular}

Patient characteristics were analyzed according to the 2 groups (Table 1). Distal cases were predominantly female, with a higher incidence of being underweight. The prevalence of deep venous thrombosis was higher in proximal cases, whereas distal cases had a higher prevalence of indwelling intravascular devices, such as central venous catheters, pacemakers, and ventriculoatrial shunt. No difference was observed regarding the age at operation, the smoking status, the need for oxygen supply, and the prevalence of splenectomy and blood groups non- 0 . The length of the disease, defined as the time between the onset of symptoms and the surgery, revealed a late referral for both proximal and distal cases. Urgent PEA was defined as the need for surgery within 48 hours of the admission. Emergency PEA was defined as the need to bring the patient immediately to the operating room because of severe hemodynamic instability. No significant difference was found regarding the need for urgent or emergency PEA between the 2 groups, despite a trend toward more emergency and urgent operations in proximal cases. Distal cases received preoperative medication more frequently, with specific drugs for pulmonary arterial hypertension, and combination therapy was more common (13/33) compared with proximal cases (4/38). No significant difference was observed in terms of medical history, concomitant diseases, and underlying medical conditions. Only atrial fibrillation was found to 
TABLE 2. Intraoperative comparison and early postoperative outcome

\begin{tabular}{|c|c|c|c|}
\hline & Proximal & Distal & $\begin{array}{c}P \\
\text { value }\end{array}$ \\
\hline Bilateral PEA (n) & $192(86.9)$ & $95(86.4)$ & 1.000 \\
\hline $\begin{array}{l}\text { Associated } \\
\text { procedures (n) }\end{array}$ & $38(17.2)$ & $19(17.3)$ & 1.000 \\
\hline $\begin{array}{l}\text { Total CPB time } \\
\qquad(\min )\end{array}$ & $338 \pm 81(327-348)$ & $361 \pm 64(349-373)$ & .005 \\
\hline Hypothermia $\left({ }^{\circ} \mathrm{C}\right)$ & $24.0 \pm 0.9(23.9-24.1)$ & ) $23.7 \pm 1.0(23.5-23.8)$ & .003 \\
\hline $\begin{array}{l}\text { Total HCA time } \\
\text { (min) }\end{array}$ & $84 \pm 32(80-89)$ & $102 \pm 28(97-107)$ & $<.001$ \\
\hline $\mathrm{PAO}_{2} / \mathrm{FIO}_{2} 6 \mathrm{~h}$ & $284 \pm 91(271-296)$ & $280 \pm 112(259-301)$ & .758 \\
\hline MV duration (d) & $2(1-3)$ & $2(1-4)$ & .565 \\
\hline ICU stay (d) & $4(3-7)$ & $4(3-8)$ & .962 \\
\hline \multirow[t]{2}{*}{$\begin{array}{l}\text { Postoperative } \\
\text { hospital stay (d) }\end{array}$} & $13(10-16)$ & $13(11-17)$ & .541 \\
\hline & Risk & $\begin{array}{c}\text { Risk difference } \\
\quad(95 \% \mathbf{C I})\end{array}$ & $P$ value \\
\hline \multicolumn{4}{|l|}{ Univariate analysis } \\
\hline \multicolumn{2}{|l|}{ Hospital mortality } & $1.8(-4.2$ to 7.9$)$ & .647 \\
\hline Proximal & $6.3 \%$ & & \\
\hline Distal & $8.1 \%$ & & \\
\hline \multicolumn{2}{|c|}{ Lung reperfusion edema } & $-0.5(-4.4$ to 3.4$)$ & 1.000 \\
\hline Proximal & $3.2 \%$ & & \\
\hline Distal & $2.7 \%$ & & \\
\hline Tracheostomy & & $-1.9(-7.8$ to 3.9$)$ & .662 \\
\hline Proximal & $8.3 \%$ & & \\
\hline Distal & $6.4 \%$ & & \\
\hline Neurologic even & & $-4.7(-10.6$ to 1.1$)$ & .209 \\
\hline $\begin{array}{l}\text { Proximal } \\
\text { transient } 13 \\
\text { permanent }\end{array}$ & $\begin{array}{l}122 \\
/ 22\end{array}$ & & \\
\hline $\begin{array}{l}\text { Distal } \\
\text { transient } 5 / \\
\text { permanent }\end{array}$ & $5.5 \%$ & & \\
\hline
\end{tabular}

Bold values indicate significance $(P<.05) . C I$, Confidence interval; $C P B$, cardiopulmonary bypass; $H C A$, hypothermic circulatory arrest; $I C U$, intensive care unit; $M V$, mechanical ventilation; $\mathrm{PAO}_{2} / \mathrm{FIO}_{2} 6 \mathrm{~h}$, partial pressure of oxygen in arterial blood/ fraction of inspired oxygen ratio 6 hours after admission to ICU; PEA, pulmonary endarterectomy.

be more frequent among proximal cases, with borderline nonsignificance.

The analysis of all the hemodynamic, echocardiographic, and functional parameters, as well as the biomarkers explored, showed no significant difference between proximal and distal cases (Table 1). All the patients presented with severe pulmonary arterial hypertension and low cardiac output, resulting in right heart failure and reduced exercise tolerance.

Bilateral PEA was performed in approximately $87 \%$ of patients, with no difference in the 2 groups (Table 2). The following associated cardiac procedures were performed: 27 patent foramen ovale closures, 17 coronary artery surgeries, 5 aortic or mitral valve surgeries, 8 parenchymal lung surgeries, and 4 right atrial or ventricular
TABLE 3. Hemodynamic time course after pulmonary endarterectomy

\begin{tabular}{|c|c|c|}
\hline & Proximal & Distal \\
\hline \multicolumn{3}{|c|}{ Mean pulmonary arterial pressure $(\mathrm{mm} \mathrm{Hg})$} \\
\hline Preoperative & $44 \pm 10$ & $46 \pm 11$ \\
\hline At discharge & $22 \pm 7$ & $24 \pm 6$ \\
\hline 3-mo follow-up & $24 \pm 9$ & $25 \pm 7$ \\
\hline 12-mo follow-up & $23 \pm 7$ & $24 \pm 8$ \\
\hline$P$ value* & $<.001$ & $<.001$ \\
\hline \multicolumn{3}{|l|}{ PVR (dyne $\left.\cdot \mathrm{s} \cdot \mathrm{cm}^{-5}\right)$} \\
\hline Preoperative & $876 \pm 392$ & $926 \pm 337$ \\
\hline At discharge & $251 \pm 146$ & $295 \pm 161$ \\
\hline 3-mo follow-up & $270 \pm 175$ & $300 \pm 139$ \\
\hline 12-mo follow-up & $243 \pm 115$ & $300 \pm 224$ \\
\hline$P$ value* & $<.001$ & $<.001$ \\
\hline \multicolumn{3}{|c|}{ Cardiac output (L/min) } \\
\hline Preoperative & $3.9 \pm 1.3$ & $3.7 \pm 1.2$ \\
\hline At discharge & $5.0 \pm 1.2$ & $4.7 \pm 1.2$ \\
\hline 3-mo follow-up & $5.2 \pm 1.1$ & $5.0 \pm 1.2$ \\
\hline 12-mo follow-up & $5.0 \pm 1.1$ & $4.7 \pm 1.0$ \\
\hline$P$ value* & $<.001$ & $<.001$ \\
\hline
\end{tabular}

thrombectomies. Both the total cardiopulmonary bypass time and the total circulatory arrest time were significantly longer in distal cases because of the need for extra dissection time. During PEA in distal cases, the level of hypothermia was slightly but significantly lower.

Good postoperative respiratory function was observed in both groups, with no difference in terms of partial pressure of oxygen in arterial blood/fraction of inspired oxygen ratio 6 hours after admission to the intensive care unit. All patients experienced similar mechanical ventilation duration, intensive care unit stay, and total postoperative hospital stay after surgery (Table 2). Overall hospital mortality was $6.9 \%$, with no difference in the 2 groups. The main causes of hospital mortality were airway bleeding $(7 / 23,30 \%)$, persistent pulmonary hypertension $(5 / 23,22 \%)$, lung infections $(5 / 23,22 \%)$, and irreversible right heart failure $(2 / 23$, $9 \%$ ). No difference was observed at univariate analysis with regard to the risk of developing lung reperfusion edema, the need for tracheostomy, and the risk of experiencing neurological events, mostly transient. Hemodynamic improvement after surgery was significant and sustained in both groups (Table 3), with normalization of mean pulmonary arterial pressure and PVR.

Postoperative follow-up after discharge was complete for 297 patients (96.4\%), with a median time of 31 (13-49) months and a total time of 9758 months. Postoperative survival was excellent in both groups (Figure 1), with no significant difference $(P=.429)$ and a hazard ratio for mortality of $0.72(0.32-1.62)$ at Cox model. Mortality rate was $4.13 \%$ $(2.74 \%-6.21 \%)$ per year and $3.13 \%(1.56 \%-6.25 \%)$ per year for proximal and distal cases, respectively. 


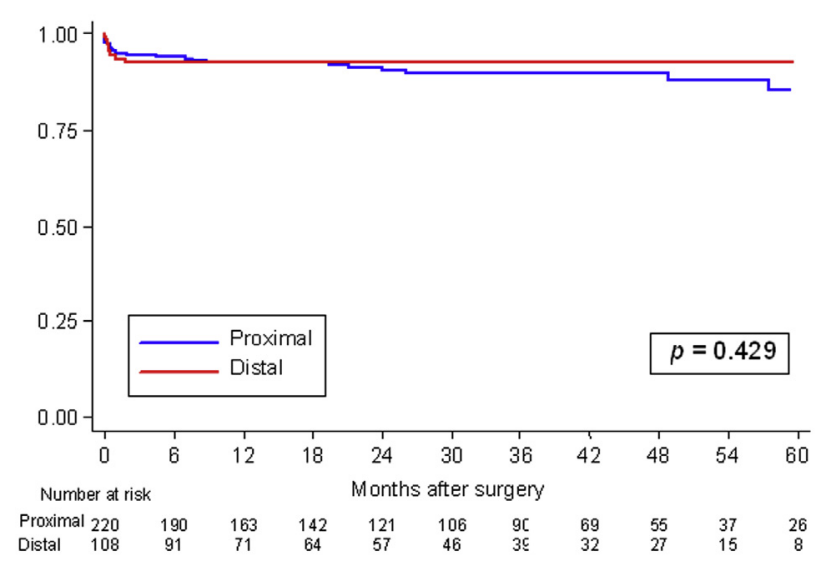

FIGURE 1. Survival after PEA.

All patients experienced a significant $(P<.001)$ change in World Health Organization (WHO) functional class early after PEA. Three months after surgery, $99 \%$ of patients were in WHO class I or II. In all patients, surgery was followed by a significant and sustained improvement in hemodynamic, echocardiographic, biochemical, and functional parameters, with no difference between proximal and distal cases. Data are shown in Tables 3, 4, and E1, and Figure E2. Comparison of time profiles between groups was assessed with test of interaction.

\section{DISCUSSION}

The main result of the present study is that PEA is a safe and effective operation in patients presenting with distal CTEPH, which is the most challenging situation. Because of the lack of regulation by the National Regulatory Authority, there is poor standardization of the diagnostic workup and treatment protocol for CTEPH, resulting in a wide variety of referral patterns. This causes frequent misdiagnosis and late diagnosis, leading to excessive delay in patient referrals, as shown by the excessive length of the disease and the high proportion of patients presenting preoperatively with WHO functional class IV symptoms.

As previously reported, ${ }^{5,21}$ there is a significant proportion of patients with operable CTEPH receiving pulmonary vasodilators agents preoperatively, contributing to the delay in patient referrals. This is significantly more frequent in cases of distal CTEPH, partially because of frequent misdiagnosis in this difficult subset of patients. Of note, 7 patients with distal CTEPH underwent PEA after having been enrolled in randomized clinical trials (Bosentan Effects in Inoperable Forms of Chronic Thromboembolic Pulmonary Hypertension [BENEFIT] trial, 2 patients, and Chronic Thomboembolic Pulmonary Hypertension Soluble Guanylate Cyclase-Stimulator Trial1 [CHEST-1] trial, 5 patients) with specific drugs for inoperable CTEPH and whose inoperability was confirmed by an external, international, dedicated committee of experienced surgeons. Because of the surgeon's learning curve, these
TABLE 4. Partial pressure of oxygen in arterial blood, modified Bruce exercise test, and 6-minute walking distance time course after pulmonary endarterectomy

\begin{tabular}{lcc}
\hline & Proximal & Distal \\
\hline Arterial partial pressure of oxygen $(\mathrm{mm} \mathrm{Hg})$ & \\
Preoperative & $65 \pm 12$ & $66 \pm 11$ \\
3-mo follow-up & $82 \pm 13$ & $80 \pm 11$ \\
12-mo follow-up & $80 \pm 11$ & $80 \pm 11$ \\
$P$ value* & $<.001$ & $<.001$ \\
Modified Bruce exercise test (m) & & \\
Preoperative & $51(0-143)$ & $52(0-102)$ \\
3-mo follow-up & $495(182-658)$ & $435(143-586)$ \\
12-mo follow-up & $520(261-709)$ & $474(225-620)$ \\
$P$ value* & $<.001$ & $<.001$ \\
6-min walking distance (m) & & $289 \pm 112$ \\
Preoperative & $277 \pm 118$ & $398 \pm 107$ \\
3-mo follow-up & $391 \pm 118$ & $396 \pm 112$ \\
12-mo follow-up & $389 \pm 118$ & $<.001$ \\
$P$ value* & $<.001$ & \\
\hline
\end{tabular}

*Each time point versus preoperative. Test of interaction: $P=.317$ (partial pressure of oxygen in arterial blood); $P=.205$ (modified Bruce exercise test); $P=.962$ (6-min walking distance).

patients were deemed operable approximately 2 years after the first assessment, despite the unchanged extent of thromboembolic obstructions. After surgery, these patients experienced a significant hemodynamic improvement (preoperative PVR $1112 \pm 367$ dyne $\cdot \mathrm{s} \cdot \mathrm{cm}^{-5}$, postoperative PVR $312 \pm 121$ dyne $\left.\cdot \mathrm{s} \cdot \mathrm{cm}^{-5}, P<.001\right)$. Unlike what has been reported anecdotally by some experienced surgeons, the preoperative use of these agents did not affect operability, because neither inflammation nor destruction of the arterial tissue planes was noticed at operation.

The operability assessment in CTEPH remains an issue. Although proximal organized lesions represent the ideal situation, preoperative imaging often tends to underestimate the amount of thromboembolic lesions, especially in patients with type 3 lesions. Lung ventilation/perfusion scan is still the most sensitive test $(>96 \%)$ for the diagnosis of CTEPH. ${ }^{22}$ With an abnormal lung scan result, the next imaging step is computed tomography for disease confirmation and operability assessment. Despite advances in computed tomography, pulmonary angiography still holds a key role especially in patients with distal lesions, mainly because of the dynamic representation of the pulmonary circulation at the subsegmental level.

Patients with distal CTEPH were predominantly female, with a significant proportion being underweight. This condition might have contributed to the more distal location of small thromboemboli. Previous deep venous thrombosis has been confirmed as an important risk factor for proximal $\mathrm{CTEPH}$, whereas the presence of indwelling intravascular devices seems to increase the risk of developing CTEPH with more distal thromboembolic obstructions. No difference was observed in the 2 groups with regard to other recognized risk factors for the development of 
CTEPH, that is, splenectomy, blood groups non- 0 , and history of cancer. ${ }^{23-25}$ Despite borderline nonsignificance, preoperative atrial fibrillation was present more frequently among proximal cases, probably because of the impact of the higher upstream pressure ${ }^{15}$ on right heart function in proximal CTEPH.

All of the hemodynamic, laboratory, echocardiographic, and functional parameters explored showed severe CTEPH in both groups, causing significant right heart failure and reduced functional capacity, regardless of disease location. By using our alternative cardiopulmonary bypass strategy, PEA was performed safely in distal cases despite long cumulative circulatory arrest times, and the extra dissection time allowed more distal disease to be cleared effectively. Although type $3 \mathrm{CTEPH}$ represents the most challenging situation, the surgical outcomes of proximal and distal cases were similar. Of note, the incidence of postoperative lung reperfusion edema was low, unlike what is reported in the literature even in most experienced centers. ${ }^{3,20}$

Although a complete recovery was shown in both groups of patients after successful operations, a subset of 15 patients (proximal disease in 14, distal disease in 1) remained with moderate-to-severe tricuspid regurgitation at 12-month follow-up, with persistent right ventricle dilation $(32 \pm 4$ $\mathrm{mm}$ ), likely due to the failure of the right ventricle to remodel after surgery. No correlation was observed with the length of the disease. Of these patients, $4(27 \%)$ were aged more than 70 years at surgery. Only 1 of these patients remained in WHO functional class III after surgery; all of the other patients were in WHO class I or II at 12-month followup, with PVR of $335 \pm 284$ dyne $\cdot \mathrm{s} \cdot \mathrm{cm}^{-5}, 6$-minute walking distance of $373 \pm 131 \mathrm{~m}$, and modified Bruce exercise test of $412 \pm 214 \mathrm{~m}$. Five $(33 \%)$ of these patients were receiving specific pulmonary vasodilators preoperatively, and 3 patients continued to receive the same drug postoperatively. None of the other 12 patients were treated with pulmonary vasodilators postoperatively. A further evaluation with cardiac magnetic resonance or endomyocardial biopsy could better characterize this peculiar subset of patients.

No difference was observed with regard to hospital mortality and long-term survival in the 2 groups, confirming that PEA can be performed safely even in distal CTEPH. Overall operative mortality is high compared with other large contemporary series reported by experienced institutions. This could be due to the rate of patients presenting with WHO class IV symptoms at operation, which is still high in our experience $(112 / 331,33.8 \%)$, and to the increasing number of elderly patients $(118 / 331,35.6 \%)$. No patient has ever been excluded from surgery on the basis of age and preoperative conditions, because the only contraindication to PEA at Foundation I.R.C.C.S. Policlinico San Matteo is underlying severe parenchymal lung disease. Moreover, a substantial number of urgent or emergency operations were performed, reflecting the high number of patients presenting in poor clinical conditions, contributing to increase the overall mortality. A significant cause of operative mortality was airway bleeding. After the recent introduction of an innovative surgical technique, ${ }^{26}$ this particular cause of death has become more rare.

\section{Study Limitations}

Any retrospective study is subject to selection bias. The operation, baseline state, and outcome were obtained from existing recorded information. However, our study included all consecutive incident patients. The database was not modified over time, and all variables were collected prospectively. Case groups were identified from the same population of operated patients with CTEPH, and groups were contemporaneous. Since 2009, approximately 60 PEAs have been performed each year. Given the significant increase in the number of PEAs performed, we decided to consider patients undergoing operation from January 1, 2008 , to December 31, 2013, to make the series more homogeneous and to avoid possible bias due to the learning curve.

\section{CONCLUSIONS}

The aim of this report is to raise the awareness of the fact that the diagnosis of inoperable CTEPH should be achieved by an experienced surgeon in an experienced center, because many patients who have been deemed inoperable might be operable and could benefit from excellent surgical outcomes. Consideration about the administration of medical therapy for patients with CTEPH should occur only after surgical assessment, because currently available drugs are not alternatives to PEA. ${ }^{27}$ Therefore, a second opinion from another experienced center might be useful before considering the patient as inoperable. The mere location of thromboembolic lesions should not deter the referral of patients to experienced centers, because this delay might be associated with the development of secondary pulmonary arteriopathy, the progression of pulmonary hypertension, and the irreversible damage of the obstructed pulmonary arteries ${ }^{28}$ resulting in worsening of surgical candidacy. In experienced centers, despite the fact that distal CTEPH represents the most challenging situation, the postoperative outcomes of both proximal and distal cases are excellent. As an ethical consideration, this becomes particularly meaningful because PEA should maximize the use of scarce organ donors by offering a nontransplant option to patients with distal CTEPH.

\section{References}

1. Galiè N, Hoeper MM, Humbert M, Torbicki A, Vachiery JL, Barbera JA, et al. Guidelines for the diagnosis and treatment of pulmonary hypertension: the Task Force for the Diagnosis and Treatment of Pulmonary Hypertension of the European Society of Cardiology (ESC) and the European Respiratory Society (ERS), endorsed by the International Society of Heart and Lung Transplantation (ISHLT). Eur Heart J. 2009;30:2493-537.

2. Jaff MR, McMurtry MS, Archer SL, Cushman M, Goldenberg N, Goldhaber SZ, et al. Management of massive and submassive pulmonary embolism, iliofemoral deep vein thrombosis, and chronic thromboembolic pulmonary hypertension: a 
scientific statement from the American Heart Association. Circulation. 2011; $123: 1788-830$.

3. Mayer E, Jenkins D, Lindner J, D’Armini A, Kloek J, Meyns B, et al. Surgical management and outcome of patients with chronic thromboembolic pulmonary hypertension: results from an international prospective registry. J Thorac Cardiovasc Surg. 2011;141:702-10.

4. Jamieson SW, Kapelanski DP, Sakakibara N, Manecke GR, Thistlethwaite PA, Kerr KM, et al. Pulmonary endarterectomy: experience and lessons learned in 1,500 cases. Ann Thorac Surg. 2003;76:1457-64.

5. Madani MM, Auger WR, Pretorius V, Sakakibara N, Kerr KM, Kim NH, et al, Pulmonary endarterectomy: recent changes in a single institution's experience of more than 2,700 patients. Ann Thorac Surg. 2012;94:97-103.

6. D’Armini AM, Zanotti G, Ghio S, Magrini G, Pozzi M, Scelsi L, et al. Reverse right ventricular remodeling after pulmonary endarterectomy. J Thorac Cardiovasc Surg. 2007;133:162-8.

7. Ghio S, Morsolini M, Corsico A, Klersy C, Mattiucci G, Raineri C, et al. Pulmonary arterial compliance and exercise capacity after pulmonary endarterectomy. Eur Respir J. 2014;43:1403-9.

8. Corsico AG, D'Armini AM, Cerveri I, Klersy C, Ansaldo E, Niniano R, et al. Long-term outcome after pulmonary endarterectomy. Am J Respir Crit Care Med. 2008;178:419-24.

9. Morsolini M, Nicolardi S, Milanesi E, Sarchi E, Mattiucci G, Klersy C, et al. Evolving surgical techniques for pulmonary endarterectomy according to the changing features of chronic thromboembolic pulmonary hypertension patients during 17-year single-center experience. J Thorac Cardiovasc Surg. 2012;144: $100-7$.

10. Thistlethwaite PA, Mo M, Madani MM, Deutsch R, Blanchard D, Kapelanski DP, et al. Operative classification of thromboembolic disease determines outcome after pulmonary endarterectomy. J Thorac Cardiovasc Surg. 2002; $124: 1203-11$.

11. Thistlethwaite PA, Kemp A, Du L, Madani MM, Jamieson SW. Outcomes of pulmonary endarterectomy for treatment of extreme thromboembolic pulmonary hypertension. J Thorac Cardiovasc Surg. 2006;131:307-13.

12. Dartevelle P, Fadel E, Mussot S, Chapelier A, Hervé P, de Perrot M, et al. Chronic thromboembolic pulmonary hypertension. Eur Respir J. 2004;23:637-48.

13. Freed DH, Thomson BM, Berman M, Tsui SS, Dunning J, Sheares KK, et al. Survival after pulmonary thromboendarterectomy: effect of residual pulmonary hypertension. J Thorac Cardiovasc Surg. 2011;141:383-7.

14. Kim NH, Fesler P, Channick RN, Knowlton KU, Ben-Yehuda O, Lee SH, et al. Preoperative partitioning of pulmonary vascular resistance correlates with early outcome after thromboendarterectomy for chronic thromboembolic pulmonary hypertension. Circulation. 2004;109:18-22.

15. Toshner M, Suntharalingam J, Fesler P, Soon E, Sheares KK, Jenkins D, et al. Occlusion pressure analysis role in partitioning of pulmonary vascular resistance in CTEPH. Eur Respir J. 2012;40:612-7.

16. D'Armini AM, Cattadori B, Monterosso C, Klersy C, Emmi V, Piovella F, et al. Pulmonary thromboendarterectomy in patients with chronic thromboembolic pulmonary hypertension: hemodynamic characteristics and changes. Eur J Cardiothorac Surg. 2000;18:696-702.

17. D'Armini AM, Zanotti G, Viganò M. Pulmonary endarterectomy: the treatment of choice for chronic thromboembolic pulmonary hypertension. Ital Heart J. 2005;6:861-8.

18. Bonderman D, Skoro-Sajer N, Jakowitsch J, Adlbrecht C, Dunkler D, Taghavi S, et al. Predictors of outcome in chronic thromboembolic pulmonary hypertension. Circulation. 2007;115:2153-8.

19. Jamieson SW, Auger WR, Fedullo PF, Channick RN, Kriett JM, Tarazi RY, et al. Experience and results with 150 pulmonary thromboendarterectomy operations over a 29-month period. J Thorac Cardiovasc Surg. 1993;106:116-27.

20. Jenkins DP, Madani M, Mayer E, Kerr K, Kim N, Klepetko W, et al. Surgical treatment of chronic thromboembolic pulmonary hypertension. Eur Respir J. 2013;41:735-42.

21. Jensen KW, Kerr KM, Fedullo PF, Kim NH, Test VJ, Ben-Yehuda O, et al. Pulmonary hypertensive medical therapy in chronic thromboembolic pulmonary hypertension before pulmonary thromboendarterectomy. Circulation. 2009;120: 1248-54.

22. Kim NH, Delcroix M, Jenkins DP, Channick R, Dartevelle P, Jansa P, et al. Chronic thromboembolic pulmonary hypertension. J Am Coll Cardiol. 2013; 62:D92-9.

23. Bonderman D, Wilkens H, Wakounig S, Schäfers HJ, Jansa P, Lindner J, et al. Risk factors for chronic thromboembolic pulmonary hypertension. Eur Respir J. 2009;33:325-31.
24. Pepke-Zaba J, Delcroix M, Lang I, Mayer E, Jansa P, Ambroz D, et al. Chronic thromboembolic pulmonary hypertension $(\mathrm{CTEPH})$ : results from an international prospective registry. Circulation. 2011;124:1973-81.

25. Lang IM, Simonneau G, Pepke-Zaba JW, Mayer E, Ambrož D, Blanco I, et al Factors associated with diagnosis and operability of chronic thromboembolic pulmonary hypertension. A case-control study. Thromb Haemost. 2013;110: 83-91.

26. Morsolini M, Azzaretti A, Orlandoni G, D’Armini AM. Airway bleeding during pulmonary endarterectomy: the "bubbles" technique. J Thorac Cardiovasc Surg. 2013;145:1409-10

27. Condliffe R, Kiely DG, Gibbs JS, Corris PA, Peacock AJ, Jenkins DP, et al Improved outcomes in medically and surgically treated chronic thromboembolic pulmonary hypertension. Am J Respir Crit Care Med. 2008;177:1122-7.

28. Galiè N, Kim NH. Pulmonary microvascular disease in chronic thromboembolic pulmonary hypertension. Proc Am Thorac Soc. 2006;3:571-6.

\section{Discussion}

Dr Michael Madani (La Jolla, Calif). It is a pleasure to see that CTEPH and PEA are finally getting recognition that they are no longer obscure diseases and obscure operations that are performed in a few centers around the world, but still there is a lot of work that needs to be done and is ahead of us.

As you know, we have performed more than 3000 of these operations at our institutions, and our referrals are increasing and there are many patients with distal disease, but we believe the disease is still severely underdiagnosed in the United States and around the world.

Furthermore, as you pointed out, what is even more disturbing is that patients are not being referred for surgery because of lack of experience in determining who is and is not operable in so-called distal disease. Congratulations on showing that even in this patient population, you can achieve significant hemodynamic improvement and potential cure.

I have 3 questions for you. First, I'm puzzled by your technique of multiple intermittent circulatory arrest of 5 to 10 minutes, each of which results in approximately 100 minutes of circulatory arrest and 6 hours of bypass. Why do you use this technique?

Dr Grazioli. The technique we use consists of moderate hypothermia at 24 degrees, short arrest session from 7 to 10 minutes, and reperfusion periods for more than 5 minutes. We arrived at this last management with a gradual change. We use this technique for 2 principal reasons: to have more neurologic protection because of reperfusion periods and monitoring of cerebral blood flow saturation and to allow a longer time for dissection to accurately remove distal lesions. This technique allows us to explore the segmental branches that can appear patent at CT scan or angiography.

Dr Madani. I somewhat disagree with that approach, and I don't think it's necessarily superior or equivalent to multiple studies showing that you can have 1 circulatory arrest time. The average time is approximately 15 to 20 minutes. You need approximately 5 to 10 minutes just to have the bloodless field when you get into distal vessels, and there are several studies that have shown that approach to be safe. My second question relates to that because in your series, the mortality is still approximately $6.9 \%$. Is that related to this or are you doing anything to improve on the mortality overall.

Dr Grazioli. We think the mortality of $7 \%$ is the same when we used the first technique. However, this mortality is high, $7 \%$ is high, and this is due to the late referral of the patients at our center. 
We sometimes have patients with an advanced disease, in functional class IV. For this reason, we try to discern this disease at another center.

Dr Madani. My last question is related to the incidence of tricuspid regurgitation. Approximately $20 \%$ of patients had moderate or severe tricuspid regurgitation. Do you do anything with those patients medically or surgically? Twenty percent with moderate to severe disease seemed somewhat high.

Dr Grazioli. Generally we don't treat tricuspid regurgitation with surgery because after PEA there is right ventricle remodeling; consequently, there is an improvement of tricuspid regurgitation.
We have performed a study on right ventricle remodeling, and in this study $70 \%$ of patients had moderate or severe regurgitation before surgery, and after there was a reduction at $16 \%$. Well, we don't say exactly the percentage of patients with moderate-severe tricuspid regurgitation is high after surgery, but the reduction is significant; however, we will try to improve this.

Dr Jose Pomar (Barcelona, Spain). So it means that you don't do tricuspid annuloplasty before?

Dr Grazioli. No.

Dr Pomar. You don't do it?

Dr Grazioli. No, we don't. 


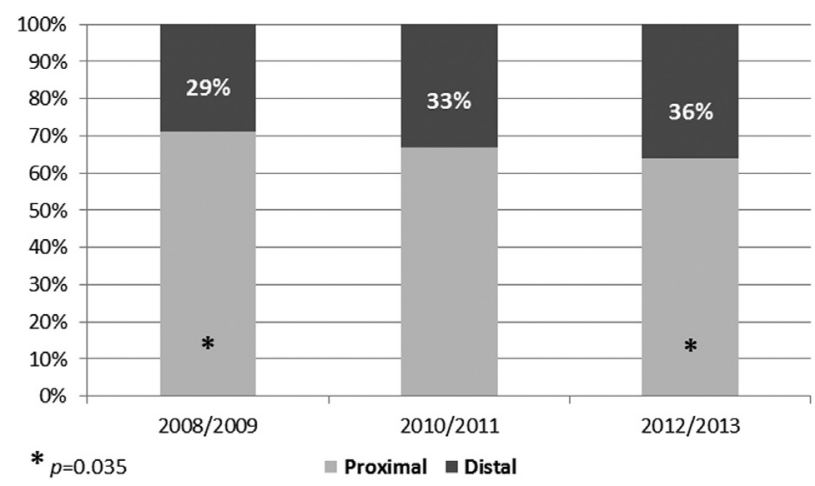

FIGURE E1. PEA operations performed by intraoperative Jamieson's classification.
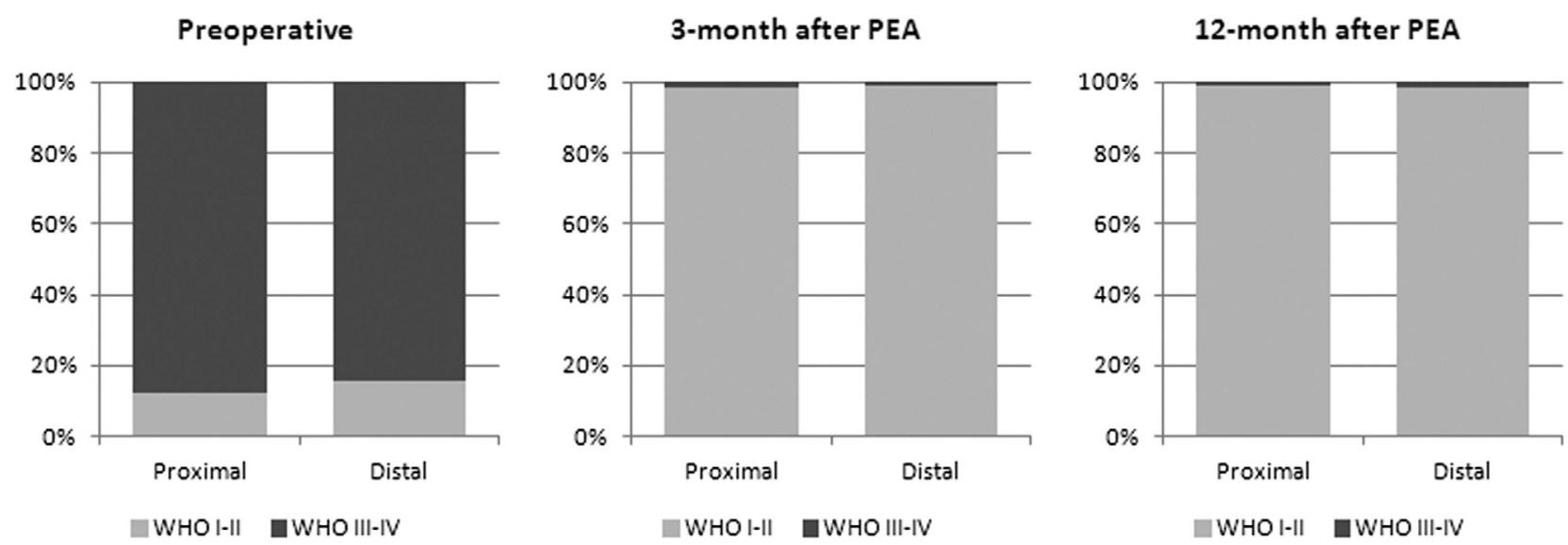

FIGURE E2. WHO functional class changes after PEA. $P<.001$ at each time point versus preoperative. Test of interaction: $P=.327 . P E A$, Pulmonary endarterectomy; $W H O$, World Health Organization. 
TABLE E1. Tricuspid regurgitation, B-type natriuretic peptide, and $\mathrm{N}$-terminal prohormone of B-type natriuretic peptide time course after pulmonary endarterectomy

\begin{tabular}{lcc}
\hline & Proximal & Distal \\
\hline Moderate/severe tricuspid regurgitation $(\%)$ & \\
Preoperative & $146(66.4)$ & $75(68.2)$ \\
3-mo follow-up & $23(16.2)$ & $14(16.5)$ \\
12-mo follow-up & $14(17.3)$ & $1(2.7)$ \\
$P$ value* & $<.001$ & $<.001$ \\
BNP (Log-[pg/mL]) & & \\
Preoperative & $5.1 \pm 1.4$ & $5.0 \pm 1.3$ \\
At discharge & $5.5 \pm 0.7$ & $5.7 \pm 0.7$ \\
3-mo follow-up & $4.3 \pm 0.8$ & $4.1 \pm 0.8$ \\
12-mo follow-up & $4.1 \pm 1.0$ & $3.8 \pm 0.8$ \\
$P$ value* & $<.001$ & $<.001$ \\
N-terminal prohormone of BNP (Log-[pg/mL]) & \\
Preoperative & $7.0 \pm 1.4$ & $6.8 \pm 1.4$ \\
At discharge & $7.0 \pm 0.8$ & $7.0 \pm 0.7$ \\
3-mo follow-up & $5.7 \pm 1.0$ & $5.5 \pm 0.9$ \\
12-mo follow-up & $5.4 \pm 1.0$ & $5.2 \pm 0.9$ \\
$P$ value $\dagger$ & $<.001$ & $<.001$ \\
\hline$B N P$, B-type natriuretic peptide. $*$ Each time point versus preoperative. $\dagger$ Each time \\
point versus preoperative (except at discharge). Test of interaction: $P=.143$ \\
(tricuspid regurgitation); $P=.098$ (B-type natriuretic peptide); $P=.276$ (N-terminal \\
prohormone of B-type natriuretic peptide).
\end{tabular}

